\title{
Continuing Professional Development for Lecturers at the National University of Lesotho: Milestones and Challenges
}

\author{
Tebello Tlali
}

\begin{abstract}
This article appraises efforts by the National University of Lesotho (NUL) to provide continuing professional development for lecturers. The findings of a previous study suggested that the majority of lecturers at this university were not trained as teachers, and that this could negatively impact on their teaching. The establishment of a staff academic development centre was long overdue. In April 20I4, the university established the Centre for Teaching and Learning (CTL). Drawing on a constructivist perspective, a qualitative approach was adopted to explore the current situation. The findings indicate that efforts to roll out continuing professional development for lecturers have not borne any significant results. The problem is exacerbated by a lack of support from the university community as well as lecturers' poor attendance at the staff academic development workshops hosted by the CTL. It is thus recommended that management put mechanisms in place to support the centre and ensure compulsory staff participation.
\end{abstract}

Key words: Higher education; continuing professional development; academic development; policy development; quality teaching and learning

Cet article vise à évaluer les moyens mis en place par l'Université Nationale du Lesotho (National University of Lesotho ou NUL) pour offrir une formation professionnelle continue aux Maîtres de conférence. Une précédente recherche a démontré que la majorité des Maîtres de conférence de cette université ne recevait pas de formation en tant qu'enseignants, ce qui pouvait avoir un impact négatif sur leur activité d'enseignement. Il était 
donc grand temps de créer un centre de formation pour le personnel universitaire. En avril 20I4, l'université a inauguré un Centre d'Enseignement et d'Apprentissage (Centre for Teaching and Learning ou CTL). A partir d'un point de vue constructiviste, la situation actuelle a été examinée selon une approche qualitative. Les résultats de cette recherche indiquent que les moyens mis en place pour proposer aux Maîtres de conférence une formation professionnelle continue n'ont pas été concluants. Le problème est accentué par un manque de soutien de la part de la communauté universitaire et par les absences répétées des Maîtres de conférence aux ateliers de formation organisés par le CTL pour le personnel universitaire. Il serait pertinent que la direction mette en place des mécanismes permettant de soutenir le Centre et de rendre la participation du personnel obligatoire.

Mots clés : Etudes supérieures, formation professionnelle continue, formation des universitaires, développement de politiques, enseignement et apprentissage de qualité

\section{Background}

In an increasingly competitive higher education (HE) environment, it is critical for higher education institutions to transform and strive for quality teaching and learning (Biggs and Tang, 20II). The National University of Lesotho (NUL), which was established in I975, was for many years the only university in the country (Ntimo-Makara, 2009). The landscape changed in 2008 with the establishment of a Malaysian Limkokwing University satellite campus; and later in $20 \mathrm{I} 6$ when Botho University (with its origins in Botswana) branched out into Lesotho. However, the NUL continues to cater for more than 50 percent of HE students in the country.

The NUL's current student population exceeds 9,000 and there are around 300 lecturers, 30 percent of whom hold PhDs (NUL - CHE Report, 20I8). While these figures may suggest a fair student-lecturer ratio of I:30, this is not necessarily the case as the student population is unevenly distributed across faculties. For instance, Natural Science faculties have far fewer students than the Social Sciences/Humanities. As a result, class sizes vary from ten to 400 students. Furthermore, the majority of the lecturers have no training in teaching and assessment.

\section{Problem Statement}

The NUL recognises the value of quality teaching and learning. As stated in its strategic plan, it aspires to be "a university of choice providing high quality educational experience and relevant scholarship". The institution also seeks to "improve student educational experience and competences" (NUL Strategic Plan, 20I5, p. 20-2I). The strategic plan notes the need to 
enhance teaching and learning by providing continuing academic staff development, among other mechanisms. However, external criticism and negative publicity continue to blemish the university's image, amidst allegations that standards have declined sharply over the past 30 years. According to Ntsukunyane (Lesotho Times, May 26, 20I6), management concedes that the institution is facing a myriad of challenges. It seems to have fallen way behind its peers not just in the region, but globally and has dropped in global rankings. The NUL is rated number 166 globally, with even universities which broke away from it rated higher (the Universities of Botswana and Swaziland, at number 44 and 99, respectively).

Ntsukunyane (Lesotho Times, May 26, 20I6) noted that the serious problems confronting the NUL include a lack of quality teaching (Motsoeli in Lesotho Times, June 23, 20II; Lloyd in Public Eye, September 7, 2012). A number of studies have confirmed that this issue cuts across Lesotho's higher education institutions (Mahao, 2003; Ministry of Education and Training, 2005; the Council of Higher Education of Lesotho, 2010).

Tlali (2OI4) and Tlali and Jacobs (2OI5) also suggested that teaching and assessment practices at the NUL need to be strengthened. The establishment of the Centre for Teaching and Learning (CTL) in 2014 was thus a much needed development for this institution. The CTL's mandate is to build capacity by providing continuing professional development in higher education teaching and related topics, namely, methods of teaching in different disciplines; assessment in higher education; the use of information technology (IT) in teaching in higher education; assisting tutors with basic counselling skills; and supporting students by equipping them with study skills.

Whilst the establishment of the CTL was a positive development, it was noted that, given the enormity of the challenges facing the NUL, it would not be easy to turn the situation around and that transformation would require considerable effort and commitment. It is against this background that this article appraises efforts to provide continuing professional development for lecturers since the establishment of the CTL.

\section{Theoretical Grounding}

The literature notes that, in order to rise to emerging challenges in the HE environment, institutions need to reposition themselves by repackaging knowledge (Le Grange, 2006; Singh, 20II). In this context, transformation requires ongoing capacity building and reflection that helps educators to seek more student-centered (constructivist) approaches, among others (Biggs and Tang, 20II). Constructivism is the most common theoretical perspective employed to scaffold deep/quality learning (Vanderstraeten, 2002). This theoretical perspective is associated with metaphors of building 
or construction which are used to illustrate how learners acquire and internalise knowledge. Constructivism is premised on the notion that learning is enhanced when learners use their own activities to construct knowledge as interpreted through their own existing schemata (Biggs and Tang, 20II).

Constructivism is rooted in the thinking of John Dewey, Jean Piaget and Lev Vygotsky (Sutinen, 2008; Vanderstraeten, 2002). Dewey's ideas are regarded as the most relevant for this article. From a Deweyan point of view, constructivism acknowledges that knowing is not a passive registration of the external world, but an active creation or building process (Sutinen, 2008; Vanderstraeten, 2002). Unlike other theoretical perspectives such as behaviourism which perceive the learner as a recipient of external stimulation, constructivism emphasises the centrality of action as well as the active nature of learning. This view is captured in John Dewey's famous principle of 'learning by doing'. In terms of this principle, experience, learning and knowing result from doing or the learner's active involvement. It is thus important to unpack the notion of deep learning and contrast it with surface learning, with a view to highlighting the features of these concepts.

\section{Deep Versus Surface Learning}

Quality teaching and learning is a key area in the HE landscape. As a research field, it deals with teaching and learning approaches (deep and surface) and the factors that influence them (Tlali and Jacobs, 20I5). Deep learning and its antonym, surface learning, are two distinct learning approaches that were initially conceptualised by Marton and Saljo in their I976 study (Biggs and Tang, 20II). In essence, deep learning involves the learner's ability to go beyond the surface, and thereby grasp the core of the learning material. It also implies the ability to figure out how the individual pieces of learning material constitute the whole (Baeten, Kyndt, Stryven, and Dochy, 20I0; Biggs and Tang, 20II). Deep learning originates from the learner's aspiration to use high cognitive skills with the aim of accomplishing the task accurately and meaningfully. Students who adopt a deep approach to learning are able to formulate knowledge which is highly structured and coherent. This results in the development of relational responses to tasks, long-term retention, improved understanding, and the ability to apply knowledge to novel situations, as well as to generate new meanings.

In contrast, students that adopt the surface learning approach tend to browse the learning material superficially, thereby reducing learning to reproduction. A surface approach only engages lower cognitive levels, resulting in a limited understanding of concepts. It also results in inability to distinguish principles from examples, and difficulties in developing a logical argument and in identifying the key ideas. Unconnected facts are passively accepted and memorised for reproduction when required (Fisher, 
2003). The symptoms of surface learning include listing points without constructing an argument and presenting a verbatim recollection of information without interpreting or demonstrating critical reflection thereon. In addition, the student finds it difficult to apply the information in novel situations (Baeten et al., 2010).

It should be noted that the educator's approach is a critical determinant of a particular learning approach (deep or surface). A good educator does not simply display information for learners to absorb. Rather he or she motivates them to take responsibility for their own learning (Cooner, 20IO). His or her focus is not solely on what he or she does, but mainly on what the students do. Such an educator is also aware that how he or she assesses performance has a bearing on how students learn. As such it is crucial for educator-learner approaches to be in sync (Tek-Yew, 20II).

Factors which inhibit deep learning include a lack of reflection, professional training, and resources as well as insufficient time to engage in practices that contribute to deep learning (Smith and Colby, 2007). It is for this reason that Smith and Colby (2007) argue that it is important for educators to undergo academic professional development which focuses on teaching and learning as a field and promotes understanding of what deep learning means and how it can be nurtured. Higher education institutions thus need to make deliberate efforts to promote deep learning rather than leaving it to chance. This responsibility is often delegated to their academic staff development units or centres (Frick and Kapp, 2009).

\section{The Role of Institutional Culture}

Institutional culture plays a fundamental role in successful transformation of $\mathrm{HE}$ institutions, and cascades into the efficient functioning of academic staff development centres. Goffee and Jones (1996) note, that, the institutional culture is crucial not only in identity formation, but also in keeping the institution intact during challenging times. Furthermore, such a culture is typified by shared values and beliefs, as well as more concrete ways of uniting a group of people, such as practices and rituals (Nieman, 20IO).

As Young (2007) rightly observes, whether or not the objective of change is positive, it often involves much personal and institutional stress. Consequently, it is sometimes met with indifference, defensiveness and resistance. Against this background, it could be argued that any HE institution that wishes to achieve transformation in so far as teaching and learning are concerned, has to be driven by a positive and cohesive institutional culture. Despite HE institutions' good intentions, academic staff development centres often suffer from a "lack of resources, difficulty in achieving buy-in from all stakeholders, policy issues and a struggle to gain support from senior management" (Frick and Kapp, 2009, p. 265). 
In sum, the literature reveals that achieving quality/deep learning is not an easy road. It requires individual $\mathrm{HE}$ institutions to fully commit to their quest to transform; uphold a cohesive and quality driven institutional culture; and consciously support academic staff development initiatives to promote quality teaching.

\section{Research Design and Methodology}

A qualitative research design was adopted (Merriam, 2009; Turner, 20I0). Informants were purposively selected from NUL's seven faculties, namely, Health Sciences, Social Sciences, Law, Education, Humanities, Science and Agricultural Sciences to ensure adequate representation. A total of I4 lecturers (two from each faculty) were selected. Two academic developers from the CTL were also engaged. The researcher paid due attention to ethical issues. The informants signed informed consent letters and were assured of confidentiality and anonymity. No coercion took place and it was made clear that participation was entirely voluntary and that informants had the right to withdraw at any stage (Cohen, Manion, and Morrison, 2OII).

Data was collected during the end-of-year examinations when most lecturers were busy with marking. For the sake of convenience, a standardised, open-ended questionnaire was used to gather data (Cohen et al., 20II; Turner, 2010). The questionnaire was sent to the informants after informed consent was obtained. They filled in the responses and returned them via email. In this way, they were able to respond to the questions at a time most convenient to them (Greeff, 20II). This data collection method had advantages and drawbacks. While, on the one hand, detailed data were obtained due to the open-ended nature of the questions, on the other, it prevented further probing of the responses. Nonetheless, adequate data were obtained.

Content analysis of the CTL 2015/16 annual report was also conducted in order to identify the milestones and challenges it faced in providing continuing professional development for NUL lecturers. This helped to enhance methodological crystallisation (Strydom and Delport, 20II). Strategies such as respondent validation (Birt, Scott, Cavers, Campbell, and Walter, 20I6) where the interpreted data was shared with the respondents to check its accuracy and its resonance with their views and experiences were also used. Direct quotations are used in this article to enhance authenticity.

\section{Findings}

This section integrates the findings from the open-ended questionnaire and the content analysis. Overlapping themes in these data sets are syn- 
thesised, while providing direct quotations. The findings focus on three main constructs, namely the milestones, challenges, and envisaged steps to improve the roll out of continuing professional development at the NUL. The section also reports on lecturers' views on the training offered by the CTL.

\section{Milestones achieved by the CTL}

The establishment of the CTL was itself an important milestone in the NUL's quest to transform teaching and assessment practices. When the centre was established in 20I4, its main mandate was to offer continuing professional development to lecturers and support student learning. The following sub-sections capture the milestones achieved by the CTL towards achieving this mandate.

\section{Capacity building workshops for lecturers}

Content analysis of the 20I5/I6 CTL Annual Report reveals that the centre's mandate entails offering capacity building workshops for long serving lecturers, and orientation workshops for new lecturers. This was confirmed by the CTL respondents. As highlighted by CTL informant I:

...in keeping with the centre's mandate, the workshops focus on a number of areas including teaching in higher education and all related topics, such as assessment in higher education; advancing the scholarship of teaching and learning; use of IT in teaching in higher education; developing a teaching philosophy; curriculum development; and developing a teaching portfolio.

\section{Empowering tutors}

In the NUL context, a tutor refers to a lecturer appointed to offer advice and counsel students on academic matters. The CTL has been working with tutors to empower them on how best to support student learning. As indicated by CTL informant $\mathrm{r}$ : the centre has been assisting tutors with basic counselling skills, as well as supporting students by equipping them with study skills.

\section{Supporting academic learning}

Informant 2 from the CTL added that the centre also supports student academic learning, through the use of the Learning Management System (LMS). The impact of Thuto' - the LMS, in terms of numbers of both teachers and students using it, is increasing and to us this is a positive development.

\section{Policy formulation}

The CTL also assumed responsibility for developing teaching and assess-

1. Thuto is the name given to the Learning Management System; it means Education 
ment policies. Content analysis of the 20I5/20I6 CTL Annual Report indicates that: although the mandate of the centre does not mention policy development, the centre has taken it to be implied. The CTL observed that, in achieving its mandate, it should be guided by specific policies. The 2015/2016 Annual Report adds that:

...our success depends on implementation of policies... hence in 2015/2016 the CTL developed the Teaching and learning policy, Assessment policy, and the Work-load allocation policy.

The following sub-sections focus on the challenges confronting the CTL and envisioned solutions.

\section{Challenges faced by the CTL}

In terms of challenges, the following themes emerged:

\section{Lack of recognition}

The analysis revealed that the CTL lacks recognition and clarification of its status. The 2015/16 CTL Annual Report notes that: the CTL's status has to be clarified either as an administration or academic unit.

\section{Lack of resources}

CTL informant I indicated that, it would seem that it will take time for change to be embraced at the National University of Lesotho, while the 2015/16 CTL Annual report observes that, the challenges range from resources to implementation..., allocated low budget, no facilities for training purposes and delay in implementing our policy and structural initiatives.

\section{Lack of human resources}

According to the 2015/I6 CTL Annual Report, the centre currently has only three staff members. This is a serious challenge given the amount of work the centre is mandated to do. In support of this standpoint, CTL informant I emphasised: we are under-staffed... there is a need for adequate staff at the centre. This will enable us to efficiently carry out our mandate.

\section{Delays in policy approval and implementation}

As noted previously, clear policies are required to guide teaching and learning, and assessment practices. While the CTL has put much effort into drafting policies, they have yet to be approved by the relevant institutional bodies. This indeed frustrates the centre. As related by CTL informant 2: It is indeed disappointing that drafted policies have still not been approved by the relevant university structures. As a result teaching and learning practices still lack a clear direction. 


\section{Poor attendance of courses}

The CTL organises orientation and staff development workshops. As indicated by CTL informant I, one of our major challenges is poor attendance of workshops and seminars. It was highlighted that the highest attendance recorded was that of fifty lecturers and the lowest was five. It seems that attendance also depends on what topic/s are on offer and who the facilitator is. This is quite disappointing considering that these workshops are prepared with the target audience of about 300 lecturers.

\section{Solutions envisioned by the CTL}

Given the challenges described above, the 2015/16 CTL Annual Report lists solutions that could improve continuing professional development at the NUL. These were reiterated by the CTL respondents.

\section{Expedite policy approval and implementation}

Policy is very important in driving change and transforming teaching and assessment practices is no exception. As highlighted by CTL informant I, NUL management needs to expedite approval and implementation of the stagnating draft policies.

Soliciting support from the university community

The need for staff development workshops cannot be over-emphasised; however, it was observed that the CTL needs to solicit the support of the university community and to increase attendance. As CTL informant 2 noted:

There should be a way of encouraging attendance. For example, there should be an incentive in the promotions criteria and issuing of attendance certifcates.

\section{Increased budget}

Content analysis of the 2015/16 CTL Annual Report illustrates that one of the challenges is the low budget allocated to the centre. The CTL aims to raise funds to complement the funding it receives from the university. The Annual Report notes that this involves developing both technical and financial proposals.

The following section presents lecturers' views and experiences of the CTL academic staff development workshops.

\section{Positive experiences of the CTL workshops}

Various views emerged among lecturers on how beneficial the CTL workshops were. 
The need for continuing professional development

The workshops have helped some lecturers to realise the importance of further training and that professional development is necessary for professional growth. As noted by lecturer informant 2:

Indeed, the workshops are necessary, given that most academics, I suppose, have not been trained on educational/professional matters, in their preservice training. Of course, even those with initial training still need some refresher courses/workshops.

\section{Reflective practice}

The workshops have also helped some lecturers to reflect on their teaching. Lecturer informant 4 attended a workshop on "Teaching in the $2 \mathrm{I}^{\mathrm{st}}$ century". He highlighted that:

...this helped me to reflect on my teaching and its impact on students' learning. I realise I have to modify $m y$ teaching and increase accessibility to students, as well as embrace the technological developments.

\section{Embracing constructivism}

It was found that constructivism was emphasised in the workshops and that the importance of constructive alignment in scaffolding assessment came to the fore. Lecturer informant Io stated:

I attended one workshop on "Assessment in institutions of higher learning"... this has helped me to tie my assessment to the objectives of the course and give appropriate types of assessment as per the skill I want students to achieve.

\section{Technology assisted teaching}

The use of technology was identified as a positive aspect of the workshops: I attended about four, but I mostly appreciated training on using Thuto. It allows for easy communication with students, efficiency in administering tests, assignments and reading materials. It is very helpful when teaching large classes (lecturer informant 6).

\section{Weaknesses of the workshops}

In contrast, some of the informants felt they benefited little or nothing from the CTL workshops.

\section{Optional attendance}

The fact that the workshops are not compulsory was seen as a factor that contributes to poor attendance. Lecturer informant 7 noted:

...the workshops are necessary to fill current gaps pertaining to teaching and learning. However, they are not totally supported as shown by the poor attendance... even where workshops are attended this is intermittent or partial as 
people leave halfway for classes and other activities.

Lecturer informant I2 stated: I think the workshops are necessary even though they are not given enough support by the community, probably because attendance is not mandatory.

\section{Lack of incentives}

Lack of motivation to attend the workshops was also highlighted. Lecturer informant 6 indicated that:

There is no motivation to attend the workshops, and they are not recognisable as part of staff development. Besides, they fail to draw on needs assessment on the part of the target groups.

Lecturer informant Io suggested that, a certificate of attendance and promotion on the basis of evidence of attendance would motivate most of the lecturers to attend.

\section{Inconvenient timing}

The timing of the workshops was also seen as a limiting factor. Lecturer informant I4 observed: Most of the time the workshops are held during lecture hours. I do not prefer to miss my classes to attend CTL workshops. Lecturer informant 9 stated: the workshops are not properly publicised or communicated, and most of the time they overlap with other important university activities.

\section{Lack of follow up}

Some staff felt that CTL did not follow up on the progress of its trainees. For example, lecturer informant 3 said: I cannot say that much about the impact of these workshops. Should there have been some follow ups, I could have learnt more.

\section{Poor engagement}

Some concerns were expressed about the level of engagement in the workshops. Lecturer informant I pointed out that the workshops were short and not so engaging.

\section{Generic nature of the workshops}

Lecturer informant 6 stated that he attended one on assessment, which addressed how to formulate test and exam questions. However, he did not benefit much from that workshop because the type of assessment strategies under focus did not relate directly to his discipline's type of questions. Lecturer informant I4 said: I do not think the workshops are effective because they are not faculty specific... attending a general workshop is not very fruitful.

The findings suggest that CTL personnel and lecturers hold divergent views on the effectiveness of CTL workshops. In the final analysis, the CTL 
and NUL management need to improve the effectiveness of the training in order to improve teaching and learning at the institution.

\section{Discussion}

The literature notes that, in order to address the new challenges confronting HE, institutions need to shift to more student-centered (constructivist) approaches to teaching and learning (Biggs and Tang, 20II; Le Grange, 2006; Singh 20II; Vanderstraeten, 2002). This is precisely why the CTL was established. The NUL recognised that investment is required in academic staff development in order to achieve quality learning. The CTL is entrusted with the enormous responsibility of ensuring that the institution achieves this goal. It offers academic development workshops on diverse issues that aim to empower lecturers to improve their teaching and assessment practices. The CTL also formulates policies to regulate these practices.

While the CTL has reason to celebrate the milestones it has achieved in its first four years of existence, challenges remain. As noted earlier, it will not be easy to turn this situation around (Tlali and Jacobs, 20I5). Refitting all lecturing staff is an arduous task that calls for a review of current practices. For example, training should be discipline specific and more interactive. The centre also needs to identify effective ways to promote its workshops and follow up on its trainees.

The success of CTL is also largely dependent on support from NUL management. However, it seems that it is facing the fate suffered by many other units and centres of its nature. The challenges include a lack of resources and support from management, as well as buy-in from all stakeholders, and dealing with policy issues (Frick and Kapp 2009). In the CTL's view, issues to be addressed include its inadequate budget and staff shortages. If the NUL is serious about its vision to cultivate an institutional culture which is quality driven, it needs to provide significant support to the CTL. Successful transformation of the institution's teaching and assessment practices depends on its ability to embrace, uphold and invest in the CTL (Young, 2007).

The study also found that poor attendance at workshops is partly due to the fact that they are not recognised in promotion criteria. Furthermore, attendance is not mandatory. This can be attributed to a lack of will on the part of management. The situation is exacerbated by the fragmented institutional culture which is characterised by the lack of a shared vision, values and practices (Nieman, 20IO). Moreover, the NUL lacks concrete strategies to achieve quality teaching and assessment.

The importance of policy in driving transformation of teaching and assessment cannot be over-emphasised. As noted earlier, the NUL needs to improve policy and practice towards the achievement of quality learn- 
ing (Tlali and Jacobs, 20I5). While the CTL has invested much effort in formulating policies, these have yet to be approved and implemented. Management plays a critical role in fostering a positive and cohesive institutional culture (Nieman, 20I0). The fact that NUL management appears to suffer shortfalls in this regard has serious ramifications and could be a major impediment in realising the CTL's goal of improving staff capacity and development.

\section{Conclusion}

The key informants provided valuable information and highlighted the milestones and challenges faced by the CTL in offering academic staff development workshops. They did not hesitate to point to deficiencies even though this might have put them in bad light. Furthermore, they felt that these issues need to be addressed in order to promote quality or deep learning at the NUL. Indeed, quality HE can only be achieved by shifting from surface to deep learning. This requires the adoption of teaching and assessment practices that are anchored on a constructivist approach.

From its strategic goals, it is clear that the NUL seeks to achieve quality education through sound, meaningful teaching. However, media reports continue to cast doubts on this matter. The Ministry of Education and Training and the Council of Higher Education of Lesotho have also acknowledged that that promoting quality learning is one of the major challenges confronting HE in the country. At the NUL, deep learning may be jeopardised by inadequate professional development of lecturers, which leads to poor teaching and assessment practices. Despite poor attendance, the establishment of the CTL and the workshops it has been offering are a step in the right direction.

However, challenges remain, including insufficient resources and staff, a lack of incentives and failure to approve and implement critical policies. In addition, the NUL has not fully ignited a cohesive and quality driven institutional culture to inform its teaching and assessment practices. Embracing and scaffolding this transformation process is necessary for tangible progress. Until then, the institution's aspiration to become "a university of choice providing high quality educational experience..." (NUL Strategic Plan, 2015, p.I9) could remain elusive.

\section{References}

Baeten, M., Kyndt, E., Struyven K., and Dochy, F. (2010). Using student-centred learning environments to stimulate deep approaches to learning: Factors encouraging and discouraging their effectiveness. Educational Research Review 5, 243-260.

Biggs, J., and Tang, C. (2OII). Teaching for quality learning at university $4^{\text {th }}$ 
ed.). Berkshire: Open University Press.

Birt, L., Scott, S, Cavers, D., Campbell, C., and Walter, F. (2016). A Tool to Enhance Trustworthiness or Merely a Nod to Validation? Qualitative Health Research 26(13), I802-I8II.

Cohen, L., Manion, L., and Morrison, K. (20II). Research Methods in Education $\left(7^{\text {th }}\right.$ ed.). London and New York: Routledge Taylor and Francis Group.

Cooner, T.S. (2010). Creating opportunities in large cohorts to reflect in and on practice: Lessons learnt from a formative evaluation of students' experiences of a technology-enhanced learning design. British Journal of Educational Technology 41(2), 27I-286.

Council of Higher Education. (2010). Strategic Plan 2010/11-1014/15. Maseru: Council of Higher Education.

Fisher, J. (2003). Surface and deep approaches to business ethics. Leadership and Organisation Development Journal 24(2), 96-гог.

Frick, L., and Kapp, C. (2009). The professional development of academics: In pursuit of scholarship. In Bitzer, E. (ed.). Higher Education in South Africa: A scholarly look behind the scenes. Stellenbosch: SUN Media, pp. 255-282.

Goffee R., and Jones G. (I996). What holds the modern company together? Harvard Business Review 74(6), I33-I48.

Greeff, M. (20II). Information collecting: interviewing. In A.S. De Vos, H. Strydom, C.B. Fouche, and C.S.L. Delport (eds.), Research at Grass Roots - From the Social Sciences and Human Service Professions. $\left(4^{\text {th }} \mathrm{ed}\right.$.). Pretoria: Van Schaik, pp. 34I-375.

Le Grange, L. (2006). The changing landscape of the contemporary university. South African Journal of Higher Education 20(4), 367-37I.

Lloyd, M. (20I2). Restructuring at NUL: A Good Policy Badly Implemented. Public Eye September 7.

Mahao, L. (2003). Towards Curriculum Relevance: The Reform Experience of the National University of Lesotho. Paper presented at Regional Training Conference on Improving Tertiary Education in Sub-Saharan Africa. Accra, September 23-25.

Merriam, S.B. (2009). Qualitative Research: A Guide to Design and Implementation. San Francisco: John Wiley and Sons.

Motsoeli, N. (2OII). Half of NUL students fail. Lesotho Times, July 23.

Ministry of Education and Training (MOET). 2005. Education Sector Strategic Plan: 2005-2015. Maseru: Ministry of Education and Training.

National University of Lesotho. (20I5). Strategic Plan 2015-2020. Roma: National University of Lesotho.

National University of Lesotho. (20I8). NUL - CHE Report of 18 April, 2018. Roma: National University of Lesotho. 
Niemann, R. (20I0). Transforming an institutional culture: an appreciative inquiry. South African Journal of Higher Education 24(5), IOOI-IO24.

Ntimo-Makara, M. (2009). Good Governance for Quality Service Delivery: National University of Lesotho (NUL) Under a Microscope and Challenges therefrom. Review of Southern African Studies 12(I), 30-63.

Ntsukunyane, L. (2016). Massive Restructuring at NUL. Lesotho Times, May 26.

Singh, P. (20II). Transformation and performativity in universities in South Africa. South African Journal of Higher Education 25(6), II90-I204.

Smith, T.W., and Colby, S.A. (2007). Teaching for Deep Learning. The Clearing House 80(5), 205-210.

Sutinen, A. (2008). Constructivism and education: education as an interpretive transformational process. Stud Philos Educ 27, I-I4.

Strydom, H., and Delport, C.S.L. (2OII). Information collection: document study and secondary analysis. In De Vos, A.S., Strydom, H., Fouche, C.B., and Delport, C.S.L., Research at Grass Roots - From the Social Sciences and Human Service Professions. $4^{\text {th }}$ ed. Pretoria: Van Schaik, pp. 376- 389.

Tek-Yew, L. (20II). Exploring the relationship between the Lecturer's Approaches to Teaching and Students Approaches to Learning. A paper presented at the Enhancing Learning: Teaching and Learning Conference. Curtin University, Malaysia $20 \mathrm{II}$.

Tlali, T.V. (20I4). Towards deep learning: Exploring the teaching and learning practices at the National University of Lesotho. MA Dissertation. University of the Free State.

Tlali, T.V., and Jacobs, L. (20I5). Teaching and assessment practices at the National University of Lesotho: some critical comments. In N. Popov, C. Wolhunter, K. Ermenc, G. Hilton, J. Ogunleye, and O. Chigisheva, Quality, Social Justice and Accountability in Education Worldwide. BCES Conference Books 13(I), 229-239.

Turner, D.W. (20I0). Qualitative interview design: A practical guide for novice investigators. The Qualitative Report 15(3), 754-760.

Vanderstraeten, R. (2002). Dewey's Transactional Constructivism. Journal of Philosophy of Education 36(2), 233-246.

Young, H.L. (2007). How to Manage Change. Education for Primary Care $18,647-649$. 